EXPERIMENTAL STUDY

\title{
Subclinical adenomas in postmortem pituitaries: classification and correlations to clinical data
}

\author{
Hilke Buurman and Wolfgang Saeger \\ Institute of Pathology of the Marienkrankenhaus Hamburg, Alfredstr. 9, D-22087, Hamburg, Germany \\ (Correspondence should addressed to W Saeger; Email: saegerpatho@marienkrankenhaus.org)
}

\begin{abstract}
Objective: The aim of this study was to examine pituitary adenomas in a series of postmortem pituitaries by use of modern technologies of immunostaining, to classify the adenomas according to the current WHO classification and to analyse the possible associations to the available clinical data.

Methods: In this study, pituitaries of 3048 autopsy cases obtained from autopsy series of the years 1991-2004 were examined.

Results: A total of 334 pituitary adenomas were found in 316 pituitaries. One hundred and thirty-two sparsely granulated prolactin cell adenomas (39.5\%), 75 null cell adenomas (22.5\%) and 31 oncocytomas were diagnosed. Forty-six ACTH cell adenomas (13.8\%, 27 densely granulated, 19 sparsely granulated) and one adenoma composed of Crooke's cells were detected. Twenty-two gonadotroph cell adenomas (6.6\%), seven GH cell adenomas (four sparsely granulated, three densely granulated), one mixed GH cell-PRL cell adenoma, two TSH cell adenomas, five plurihormonal adenoma type I, four plurihormonal adenoma type II and two $\alpha$-subunit-only adenomas were seen. Six adenomas remained unclassified because the tissue was not contained in all sections for immunohistochemistry. Seventeen pituitaries included multiple tumours. The overall tumour size ranged from 0.1 to $20 \mathrm{~mm}$ in diameter. Among 76 adenomas $(22.7 \%)$, which had a tumour size of $\geq 3 \mathrm{~mm}$, only three tumours were macroadenomas corresponding to a tumour size of more than $10 \mathrm{~mm}$. The evaluation of the available clinical data showed 99 cases of hypertension, 65 cases of diabetes mellitus, six patients with hyper-thyroidism and four with hypothyroidism. No symptoms of adenohypophyseal hormone hypersecretion were reported. The statistical correlations to clinical data were discussed.

Conclusions: Adenomas in postmortem pituitaries differ from those in surgical series in proportion of adenoma types and biological behaviour.
\end{abstract}

European Journal of Endocrinology $154753-758$

\section{Introduction}

Pituitary adenomas are the most frequently encountered tumours in the pituitary gland and represent about $10 \%$ of all surgically resected intracranial neoplasms (1). In postmortem series, the incidence ranges from 3.2 to $27 \%$ (2-8). Nowadays, the diagnosis of pituitary adenomas has increased as a result of the advances in neuroimaging technologies. Classification of pituitary adenomas has changed within recent decades. First, the adenomas were classified by functional properties into chromophobic, basophilic and eosinophilic tumour types (7). Later classification of adenomas was based on immunohistochemical hormone content (9-11).

In this study, pituitaries of 3048 autopsy cases were examined to detect the incidence of subclinical adenomas in postmortem pituitaries. The aim of this study was to examine adenomas in a large collective of postmortem pituitaries by use of modern technologies to classify the adenomas according to the current WHO classification (12) and to analyse the possible correlations to the available clinical data.

\section{Materials and methods}

Pituitaries of 3048 autopsy cases obtained from autopsy series of the years 1991-2004 were examined. The tissue was fixed with $10 \%$ formalin, sectioned threedimensionally and totally embedded in paraffin. The prepared tissue samples were cut into $5 \mu$ m-thick sections and stained with haematoxylin/eosin and periodic acid/Schiff (PAS).

Immunohistochemical staining followed using an automated staining machine (DAKO Cytomation Autostainer, Hamburg, Germany) applying the avidin-biotin-peroxidase method. The following 
Table 1

\begin{tabular}{|c|c|c|c|}
\hline Adenoma type & Number of tumours & $\begin{array}{l}\text { Included cases with multiple } \\
\text { tumours }\end{array}$ & Percentage \\
\hline GH cell adenoma, sparsely granulated & 4 & - & 1.2 \\
\hline PRL cell adenoma, sparsely granulated & 132 & 12 & 39.5 \\
\hline Mixed GH cell-PRL cell adenoma & 1 & - & 0.3 \\
\hline Plurihormonal adenoma type I & 5 & - & 1.5 \\
\hline TSHoma & 2 & 1 & 0.6 \\
\hline ACTH cell adenoma, densely granulated & 27 & 3 & 8.1 \\
\hline ACTH cell adenoma, sparsely granulated & 19 & 1 & 5.7 \\
\hline Crooke's cell adenoma & 1 & - & 0.3 \\
\hline Gonadotroph cell adenoma & 22 & - & 6.6 \\
\hline$\alpha$-Subunit-only-adenoma & 2 & - & 0.6 \\
\hline Plurihormonal adenoma type II & 4 & - & 1.2 \\
\hline Null cell adenoma & 75 & 15 & 22.5 \\
\hline Oncocytoma & 31 & 3 & 9.3 \\
\hline Total & 334 & $35^{\star}$ & 100 \\
\hline
\end{tabular}

* 17 cases: 16 with 2 tumours and 1 with 3 tumours.

primary antibodies were used: anti-growth hormone (GH)-monoclonal (BioGenex, San Ramon, USA) diluted 1:200; anti-prolactin (PRL)-monoclonal (Immunotech, Marseille, France) diluted 1:400; anti-adrenocorticotrophic hormone (ACTH)-monoclonal (Novocastra, Newcastle, UK) diluted 1:400; anti-thyroid-stimulating hormone (TSH)-monoclonal (Immunotech) diluted 1:5000; anti- $\beta$ follicle-stimulating hormone $(\beta F S H)$ monoclonal (Immunotech) diluted 1:40 000; anti- $\beta$ luteinizing hormone ( $\beta \mathrm{LH})$-monoclonal (Immunotech) diluted 1:5000; anti- $\alpha$ subunit-monoclonal (Immunotech) diluted 1:1500; anti-S-100 protein (DAKO) diluted 1:1500; and ki-67 (MiB-1) (Zytomed, Berlin, Germany) diluted 1:150.

We identified the adenomas by their architecture which was sinusoidal, diffuse or solid in contrast to the alveolar basic structure of the normal pituitary and by their nearly or completely monocellular composition. Focal hyperplasias were not encountered in this study. They were differentiated from the adenomas by their nearly intact alveolar basic structure.

The available clinical data were rescreened from the files for any information about hypertension, diabetes mellitus, hypo- and hyper-thyroidism and any other endocrinological disorders.

\section{Statistical analysis}

For statistical analysis, Mann-Whitney test and Fisher's exact test were used for comparing tumour size, gender, adenoma type and clinical data. Statistical significance was established at the level of $P<0.05$.

\section{Results}

A total of 334 pituitary adenomas in 316 of 3048 pituitaries $(10.4 \%)$ were found. The cases included
157 male and 159 female patients in the age range of 28-97 years (mean 73 years).

The most frequently detected tumours were sparsely granulated PRL cell adenomas (132 cases, 39.5\%). The results of the morphological tumour type are summarized in Table 1. A total of 17 pituitaries comprised multiple tumours, 16 cases included two tumours and one case three adenomas (Table 2).

\section{GH cell adenomas}

In seven cases, tumour cells exhibited immunopositivity for GH. Tumour size varied from 0.75 to $8.8 \mathrm{~mm}$ (median $2.3 \mathrm{~mm}$, Table 3). Four sparsely granulated GH cell adenomas were composed of monomorphic medium-sized tumour cells with chromophobic or weakly acidophilic cytoplasm. Fibrous bodies were demonstrated by globular expression of Pankeratin KL 1. Three densely granulated tumours exhibited a distinct acidophilic cytoplasm.

Table 2 Multiple adenomas.

\begin{tabular}{llr}
\hline Adenoma type & & \\
\hline Largest tumour & 2nd/3rd tumour & 3 \\
\hline PRL cell adenoma & PRL cell adenoma & 4 \\
PRL cell adenoma & Null cell adenoma & 3 \\
Null cell adenoma & Null cell adenoma & 2 \\
Oncocytoma & Null cell adenoma & 1 \\
ACTH cell adenoma, densely & Null cell adenoma & \\
$\quad$ granulated & & \\
ACTH cell adenoma, densely & PRL cell adenoma & \\
$\quad$ granulated & & \\
ACTH cell adenoma, sparsely & Oncocytoma & 1 \\
granulated & & 17 \\
TSHoma & Two null cell adenomas & \\
Total & & \\
\hline
\end{tabular}




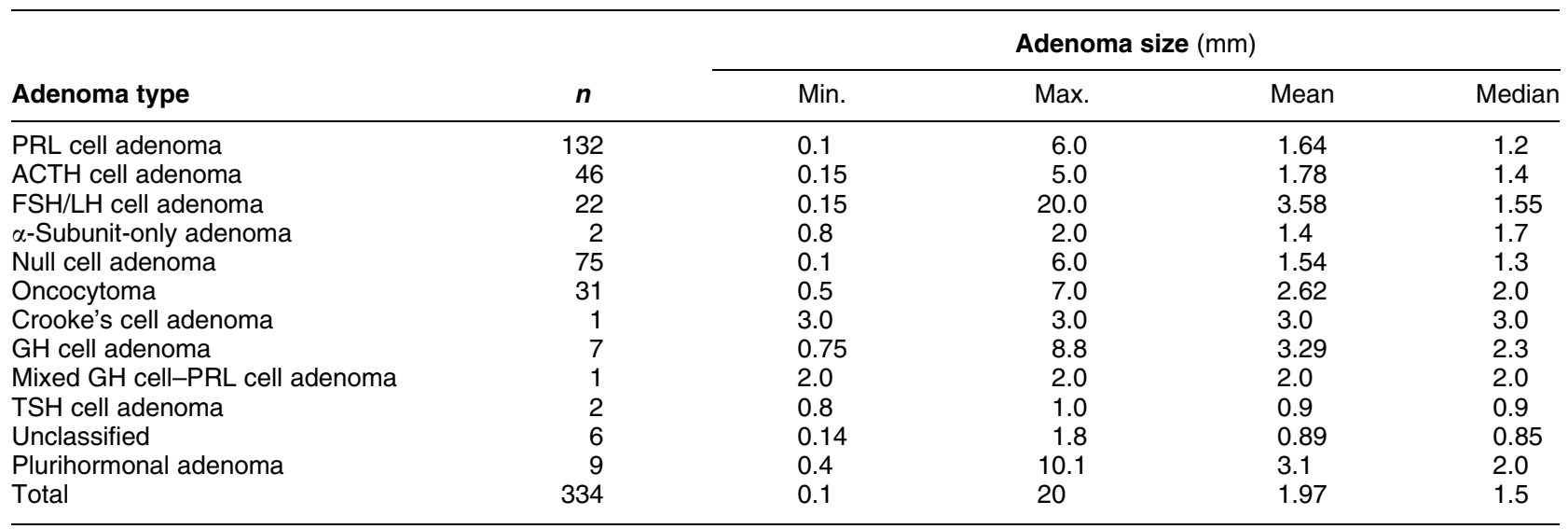

\section{PRL cell adenomas}

One hundred and thirty-two (39.5\%) of the detected adenomas were immunopositive for prolactin, ranging in size from 0.1 to $6 \mathrm{~mm}$ (median $1.2 \mathrm{~mm}$ ). The adenomas consisted of medium-sized slightly pleomorphic tumour cells with chromophobic or weakly acidophilic often elongated cytoplasm and were classified as sparsely granulated PRL cell adenomas.

\section{Mixed GH/PRL cell adenoma}

One tumour measuring $2 \mathrm{~mm}$ in diameter was immunopositive for both $\mathrm{GH}$ and prolactin, and was classified as sparsely granulated mixed GH/PRL cell adenoma.

\section{TSHoma}

Only two tumours $(0.6 \%)$ with a tumour size of 0.8 and $1 \mathrm{~mm}$ exhibited exclusive staining of tumour cells for TSH.

\section{ACTH cell adenoma/Crooke's cell adenoma}

A total of 47 tumours were counted among ACTH producing adenomas. Tumour size varied from 0.15 to $5 \mathrm{~mm}$ in diameter (median $1.4 \mathrm{~mm}$ ). Twenty-seven of the ACTH producing tumours were composed of uniform tumour cells with slightly dense chromatin and distinct PAS positive basophil cytoplasm corresponding to a densely granulated ACTH cell adenoma. Nineteen adenomas with weakly granulated PAS positive tumour cells were classified as sparsely granulated adenomas. As these cases did not show Crooke's cells in the tumour-free pituitary a distinct hypercortisolism could be excluded $(13,14)$. There was one case of Crooke's cell adenoma with Crooke's hyaline change within the tumour cells. Twenty-one ACTH cell adenomas (44.7\%) exhibited an adjacent ACTH cell hyperplasia.

\section{Gonadotroph cell adenoma}

A total of 22 adenomas were classified as gonadotroph cell adenomas, varying in tumour size from 0.15 to $20 \mathrm{~mm}$ (median $1.55 \mathrm{~mm}$ ). Two macroadenomas had tumour sizes of 12 and $20 \mathrm{~mm}$. The adenomas consisted of monomorphic cells with chromophobic cytoplasm and mostly sinusoidal growth pattern. Eleven tumours were positive for FSH and LH and eight cases were positive for FSH. One case showed immunohistochemical staining for LH, one for LH and $\alpha$-subunit and one for FSH, LH and $\alpha$-subunit.

\section{$\alpha$-Subunit-only adenoma}

Two adenomas with a tumour size of 0.8 and $2 \mathrm{~mm}$ were exclusively positive for the $\alpha$-subunit of glycoprotein hormones.

\section{Null cell adenoma/oncocytoma}

According to their definition, null cell adenomas and oncocytomas were immunonegative for any hormone, but may contain some scattered positive cells. The tumour size ranged from 0.1 to $7 \mathrm{~mm}$ (median $1.5 \mathrm{~mm}$ ). We found 75 null cell adenomas with mostly small cells and 31 oncocytomas consisting of large tumour cells with slightly acidophilic PAS negative cytoplasm.

\section{Plurihormonal adenomas}

Plurihormonal adenomas or multihormonal adenomas secreted unrelated hormones not including the combinations GH/PRL/TSH or FSH/LH. The plurihormonal adenomas varied in tumour size from 0.4 to $10.1 \mathrm{~mm}$ (median $2 \mathrm{~mm}$ ), including one macroadenoma measuring $10.1 \mathrm{~mm}$. A total of five tumours showed immunohistochemical staining for GH, PRL and glycoprotein hormones (plurihormonal adenoma type I). Four 
Table 4 Plurihormonal adenomas.

\begin{tabular}{|c|c|c|c|c|c|c|c|}
\hline Case no. & $\begin{array}{l}\text { Plurihormonal } \\
\text { adenoma type }\end{array}$ & GH & PRL & TSH & FSH & LH & $\alpha-S U$ \\
\hline 173 & I & $x$ & $x$ & $x$ & - & $x$ & $x$ \\
\hline 174 & I & $X$ & $x$ & $x$ & - & $X$ & $x$ \\
\hline 175 & I & $X$ & $x$ & $X$ & $X$ & $X$ & $X$ \\
\hline 176 & I & $X$ & $x$ & $X$ & $x$ & $X$ & $x$ \\
\hline 177 & I & $X$ & $X$ & - & $X$ & $X$ & - \\
\hline 178 & II & - & - & $x$ & $x$ & $x$ & $x$ \\
\hline 179 & II & - & - & $x$ & $X$ & $x$ & $x$ \\
\hline 180 & II & - & - & $x$ & $x$ & $x$ & $x$ \\
\hline 181 & II & $X$ & - & - & $X$ & $x$ & $x$ \\
\hline
\end{tabular}

$\alpha$-SU: $\alpha$-subunit.

tumours contained FSH, LH and TSH or GH (plurihormonal adenoma type II) (Table 4).

\section{Unclassified adenomas}

Six adenomas were unclassified due to methodical deficiency. The small tumour tissue was not contained in all sections for immunohistochemical staining. Tumour size ranged from 0.14 to $1.8 \mathrm{~mm}$ (median $0.7 \mathrm{~mm}$ ), mean $0.89 \mathrm{~mm}$.

\section{Tumour size}

The overall tumour size ranged from 0.1 to $20 \mathrm{~mm}$ in diameter (median $1.5 \mathrm{~mm}$, interquartile range, 1.65). One hundred and thirty-eight $(41.3 \%)$ tumours had a tumour size of $1 \mathrm{~mm}$ or less and 76 adenomas $(22.7 \%)$ had a tumour size of $\geq 3 \mathrm{~mm}$. Only three tumours were macroadenomas corresponding to a tumour size of more than $10 \mathrm{~mm}$ (Table 3). There has been no significant correlation between gender and tumour size (Fig. 1) or adenoma type and corresponding tumour size (Fig. 2).

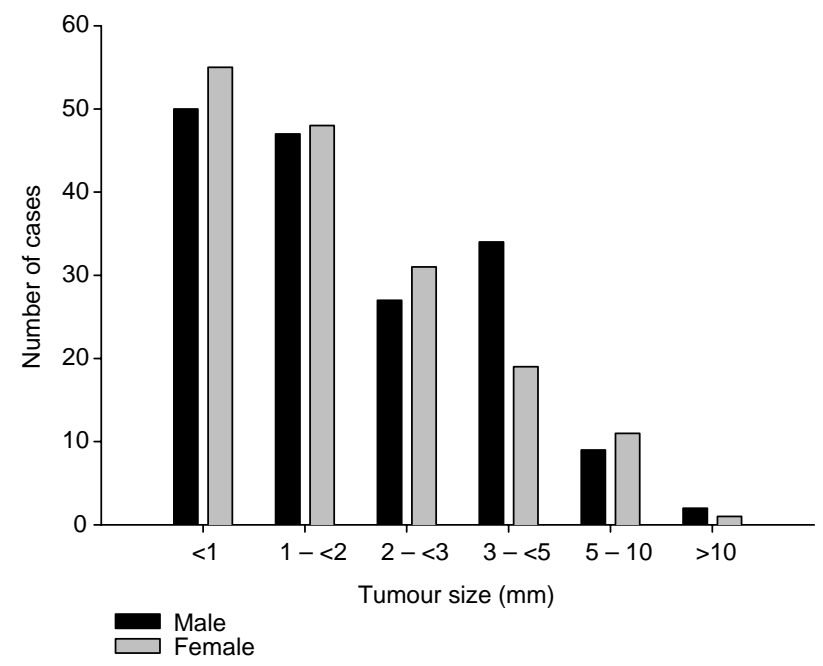

Figure 1 Gender and tumour size. Only the largest tumour is counted among the 17 cases of multiple adenomas.

\section{Clinical data}

Clinical data concerning hypertension, diabetes mellitus and other endocrinological symptoms were collected (Table 5). No symptoms of adenohypophyseal hormone hypersecretion were reported. Ninety-nine patients suffered from hypertension and 65 patients were reported to have diabetes mellitus. Cases of hyper- and hypo-thyroidism were quite rare (six and four cases respectively), but none of them exhibited a TSH cell adenoma. There was a significantly higher incidence of diabetes mellitus in the group of 'other' adenomas (TSH cell adenomas, plurihormonal adenomas without GH secretion and unclassified adenomas) (Fisher's exact test, $P=0.007)$.

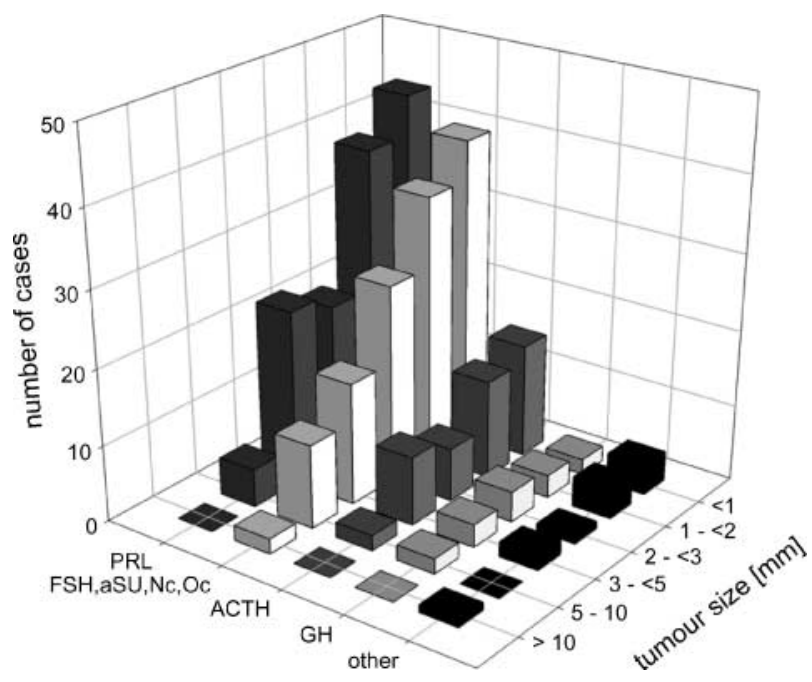

Figure 2 Adenoma type and tumour size. Only the largest tumour is counted among the 17 cases of multiple adenomas. PRL cell adenoma; ACTH, ACTH cell adenoma and Crooke's cell adenoma; $\mathrm{FSH}$, gonadotroph cell adenoma; $\alpha$-SU, $\alpha$-subunit only adenoma; $\mathrm{Nc}$, null cell adenoma; Oc, oncocytoma; GH, GH cell adenoma, mixed Gh-PRL-cell adenoma, GH secreting plurihormonal adenoma; Other, TSH cell adenoma, plurihormonal adenoma (without GH secretion), and unclassified adenoma. 
Table 5

\begin{tabular}{|c|c|c|c|c|c|}
\hline Adenoma type & Total & Hypertension & Diabetes mellitus & Hyperthyroidism & Hypothyroidism \\
\hline PRL cell adenoma & 126 & 44 & 21 & 2 & 1 \\
\hline $\begin{array}{l}\text { ACTH cell adenoma and } \\
\text { Crooke's cell adenoma }\end{array}$ & 46 & 16 & 13 & 2 & 0 \\
\hline $\begin{array}{l}\text { FSH/LH cell adenoma, } \\
\alpha \text {-SU-only adenoma, null } \\
\text { cell adenoma, } \\
\text { oncocytoma }\end{array}$ & 120 & 30 & 22 & 2 & 3 \\
\hline $\begin{array}{l}\text { GH cell adenoma, mixed } \\
\text { GH-PRL cell adenoma, } \\
\text { GH secreting plurihor- } \\
\text { monal adenoma }\end{array}$ & 14 & 3 & 3 & 0 & 0 \\
\hline Other & 10 & 6 & 6 & 0 & 0 \\
\hline Total & 316 & 99 & 65 & 6 & 4 \\
\hline
\end{tabular}

Other: TSH cell adenoma, plurihormonal adenoma (without GH secretion) and unclassified adenoma. Only the largest tumour is counted in case of multiple adenomas.

\section{Statistical evaluation}

No significant association was detectable between tumour size and sex (Mann-Whitney test). Evaluation of the data with Fisher's exact test exhibited a higher incidence of diabetes in the group of other adenomas (TSH cell adenomas, plurihormonal adenomas without GH secretion and unclassified adenomas) $(P=0.007)$. No associations between gender and adenoma type, adenoma type and hypertension or adenoma type and tumour size were evident.

\section{Discussion}

Incidence of subclinical adenomas showed no sex predominance in accordance with data in studies published previously $(2,6,15,16)$.

In some cases with very tiny adenomas, difficulties to distinguish between small adenomas and nodular hyperplasias were noticeable, but in most cases the loss of normal stromal pattern and acinar growth pattern was obvious.

Most adenomas in the present study were PRL cell adenomas (39.5\%). In previously published autopsy studies, PRL cell adenomas also represented the majority of pituitary adenomas and the incidence ranged from about 40 to $50 \%(1,3,9,17)$. In most surgical series, the incidence of prolactinomas was lower because of the medical therapeutic option of these tumours (17-19).

A total of $106(31.7 \%)$ adenomas (75 null cell adenomas and 31 oncocytomas) were identified. In the literature, the incidence of null cell adenomas or adenomas without immunohistochemical staining in postmortem pituitaries ranges from 18 to $50 \%(2,6$, 9, 20).

Forty-seven adenomas (14.1\%) were ACTH cell adenomas; one of them was composed of Crooke's cells. Other autopsy studies found lower percentages up to $7.2 \%(2,9,20)$, whereas ACTH cell adenomas represent about $15 \%$ of adenomas in surgically removed pituitary adenomas $(19,21)$.

In the current study, $6.6 \%$ of adenomas were gonadotroph cell adenomas corresponding to the findings of Abd el-Hamid et al. (2).

Only eight tumours $(2.3 \%)$ revealed positive staining for $\mathrm{GH}$, although previously reported data ranged from 0 to $18 \%$ in postmortem pituitaries $(2,6,9,20)$. Considering all surgically removed pituitary adenomas, GH cell adenomas account for $25-30 \%(22)$.

TSH cell adenomas represented only $0.6 \%$ of all adenomas in the current study.

Plurihormonal or multihormonal adenomas were classified according to the WHO classification (23), including cases secreting unrelated hormones not showing the combinations GH/PRL/TSH or FSH/LH. In the current study, these tumours were quite rare $(2.7 \%)$.

Seventeen cases $(5.4 \%)$ exhibited a total of 35 multiple adenomas. Other authors described multiple tumours in $0.9-19.4 \%(6,20,24)$. Eighteen of thirtyfive multiple adenomas were null cell adenomas or oncocytomas. Kontogeorgos et al. also reported a lack of immunohistochemical staining in the majority of multiple adenomas in autopsy material (24). In contrast to these findings Sano et al. described a predominance of GH producing adenomas in multiple adenomas detected in surgically resected material (25). These differences correspond to the observation that null cell adenomas are slow growing and may be incidentally detected without any symptoms, whereas most GH cell adenomas cause gigantism or acromegaly.

Subclinical pituitary adenomas are predominantly small with a mean tumour size of $1.9 \mathrm{~mm}$ in this study; over $30 \%$ of the detected adenomas were smaller than $1 \mathrm{~mm}$ in diameter. These findings are comparable to the results of Parent et al., who found $62 \%$ of adenomas in postmortem pituitaries to be smaller than $3 \mathrm{~mm} \mathrm{(4)} \mathrm{and}$ to a study by Teramoto et al., who found $66 \%$ of subclinical adenomas to be $2 \mathrm{~mm}$ or smaller (8). We 
encountered only three macroadenomas among the 334 adenomas. In previously published studies, subclinically or incidentally detected macroadenomas were also very rare $(3,7,26)$.

Our statistical analysis did not reveal a clear significant correlation between clinical data and adenoma type. This is in accordance with the results of McComb et al. (9). There was a higher incidence of diabetes in the group of other adenomas (TSH cell adenomas, plurihormonal adenomas without $\mathrm{GH}$ secretion and unclassified adenomas). Interpreting these results, the low number of 'other' adenomas (only 10 cases were included in this group) has to be considered. Information about fertility, libido, bone density, physical activity or emotional status was not available.

From our findings, we conclude that adenomas in postmortem pituitaries are different from those in surgical series according to the proportion of adenoma types, functional properties and biological behaviour.

\section{Acknowledgements}

The authors thank Petra Wolf for performing the immunhistochemical stainings and Dr Michael Bubenheim, Department of Medical Biometry and Epidemiology, University Medical Center Hamburg-Eppendorf, Hamburg, Germany, for expert statistical analysis.

\section{References}

1 Clayton RN. Sporadic pituitary tumours: from epidemiology to use of databases. Baillieres Best Practice \& Research. Clinical Endocrinology and Metabolism 199913 451-460.

2 Abd el-Hamid MW, Joplin GF \& Lewis PD. Incidentally found small pituitary adenomas may have no effect on fertility. Acta Endocrinologica (Kopenhagen) 1988117 361-364.

3 Burrow GN, Wortzman G, Rewcastle NB, Holgate RC \& Kovacs K. Microadenomas of the pituitary and abnormal sellar tomograms in an unselected autopsy series. The New England Journal of Medicine $1981304156-158$.

4 Parent AD, Brown B \& Smith EE. Incidental pituitary adenomas: a retrospective study. Surgery 198292 880-883.

5 Post KD \& Muraszko K. Management of pituitary tumors. Neurologic Clinics $19864801-831$.

6 Uei Y, Kanzaki M \& Yabana T. Incidental adenomas of the human pituitary gland. Endocrine Pathology 19945 90-99.

7 Costello RT. Subclinical adenoma of the pituitary gland. The American Journal of Pathology 193612 205-216.

8 Teramoto A, Hirakawa K, Sanno N \& Osamura Y. Incidental pituitary lesions in 1,000 unselected autopsy specimens. Radiology $1994193161-164$.
9 McComb DJ, Ryan N, Horvath E \& Kovacs K. Subclinical adenomas of the human pituitary. New light on old problems. Archives of Pathology E Laboratory Medicine 1983107 488-491.

10 Heitz PU. Multihormonal pituitary adenomas. Hormone Research $1979101-13$.

11 Kovacs K, Ryan N, Horvath E, Singer W \& Ezrin C. Pituitary adenomas in old age. Journal of Gerontology 198035 16-22.

12 Lloyd RV, Kovacs K, Young WF, Jr, Farrell WE, Asa SL, Trouillas J, Kontogeorgos G, Sano T, Scheithauer BW \& Horvath E. Pituitary tumours: introduction. In World Health Organization Classification of Tumours. Pathology and Genetics. Tumours of Endocrine Organs, pp 10-13. . RA DeLellis, RV Lloyd, PU Heitz \& C Eng, Lyon: IARC Press, 2004.

13 Lüdecke DK, Flitsch J, Knappe UJ \& Saeger W. Correlates of longterm hypocortisolim after transnasal microsurgery for Cushing's disease. Endocrine Pathology 19956 373-374.

14 Saeger W, Geisler F \& Ludecke DK. Pituitary pathology in Cushing's disease. Pathology, Research and Practice 1988183 592-595.

15 Camaris C, Balleine R \& Little D. Microadenomas of the human pituitary. Pathology 199527 8-11.

16 Asa SL \& Ezzat S. The cytogenesis and pathogenesis of pituitary adenomas. Endocrine Reviews 199819 798-827.

17 Ho DM \& Liu HC. Prolactin-containing pituitary adenomas. Their characteristics and comparative study with non-prolactin adenomas. Pathology, Research and Practice 1992188 296-302.

18 Terada T, Kovacs K, Stefaneanu L \& Horvath E. Incidence, pathology, and recurrence of pituitary adenomas: study of 647 unselected surgical cases. Endocrine Pathology 19956 301-310.

19 Wilson CB \& Dempsey LC. Transsphenoidal microsurgical removal of 250 pituitary adenomas. Journal of Neurosurgery 1978 48 13-22.

20 Tomita T \& Gates E. Pituitary adenomas and granular cell tumors-incidence, cell type, and location of tumor in 100 pituitary glands at autopsy. American Journal of Clinical Pathology $1999111817-825$.

21 Thapar K, Kovacs K \& Laws ER. The classification and molecular biology of pituitary adenomas. Advances and Technical Standards in Neurosurgery 199522 3-53.

22 Kontogeorgos G, Watson RE, Jr, Lindell EP, Barkan AL, Farrell WE \& Lloyd RV. Growth hormone producing adenoma. In World Health Organization Classification of Tumours. Pathology and Genetics. Tumours of Endocrine Organs, pp 14-19. . RA DeLellis, RV Lloyd, PU Heitz \& C Eng, Lyon: IARC Press, 2004.

23 Horvath E, Lloyd RV, Kovacs K, Sano T, Kontogeorgos G, Trouillas J \& Asa SL. Plurihormonal adenoma. In World Health Organization Classification of Tumours. Pathology and Genetics. Tumours of Endocrine Organs, p 35.. RA DeLellis, RV Lloyd, PU Heitz \& C Eng, 2004.

24 Kontogeorgos G, Kovacs K, Horvath E \& Scheithauer BW. Multiple adenomas of the human pituitary. A retrospective autopsy study with clinical implications. Journal of Neurosurgery $19917 \mathbf{4}$ 243-247.

25 Sano T, Horiguchi H, Xu B, Li C, Hino A, Sakaki M, Kannuki S \& Yamada S. Double pituitary adenomas: six surgical cases. Pituitary $19991243-250$.

26 Nammour GM, Ybarra J, Naheedy MH, Romeo JH \& Aron DC. Incidental pituitary macroadenoma: a population-based study. The American Journal of Medical Sciences $1997314287-291$.

Received 20 October 2005

Accepted 9 December 2005 